\title{
Evaluation of Harmonic Suppression Devices
}

\author{
Leon M. Tolbert, Member, IEEE \\ Oak Ridge National Laboratory* \\ P.O. Box 2008, Bldg 1000 \\ Oak Ridge, TN 37831-6334 \\ Phone: (423) 576-8175 \\ e-mail: tolbertlm@ornl.gov
}

\author{
Harold D. Hollis and Peyton S. Hale, Jr. \\ U.S. Army Center for Public Works, CECPW-K \\ 7701 Telegraph Drive \\ Alexandria, VA 22315-3862 \\ Phone: (703) 428-8191 \\ e-mail: Peyton.S.Hale@cpw01.usace.army.mil
}

\begin{abstract}
An assessment has been conducted of five commercially available devices to determine their ability to provide clean sinusoidal voltage to nonlinear loads and to eliminate harmonic currents demanded by nonlinear loads. The devices tested were a passive series-shunt filter, a delta-wye isolation transformer, a ferroresonant magnetic synthesizer, an active power line conditioner, and an active injection mode filter.

These devices were installed in existing Department of Energy facilities that had substantial non-linear loads which drew a significant harmonic current. These devices were then compared in the following categories: cancellation of harmonic currents, supply of nondistorted voltage, supply of regulated voltage, elimination of transients and impulses, efficiency, reliability, and cost.
\end{abstract}

\section{INTRODUCTION}

The U.S. Army Center for Public Works proposed a study to determine what devices are best for reducing or eliminating the effects of harmonics on power systems typical of those existing in their Command, Control, Communication and Intelligence (C3I) sites. Because of the number of electronics at C3I sites, these non-linear loads, composed mostly of switch mode power supplies and uninterruptible power supplies (UPS's), have strained electrical systems which largely had been designed for sinusoidal voltage and current waveforms.

As a part of this study, five different commercially available power quality improvement units (PQIU's) advertised to be universally applicable for the reduction of harmonics were tested for their ability to provide clean sinusoidal voltage to nonlinear loads and eliminate harmonic currents demanded by nonlinear loads [1]. Reference [2] is a related paper which contains some background information useful in discussing harmonics.

The devices tested were a passive series-shunt filter, a shielded delta-wye isolation transformer, a ferroresonant magnetic synthesizer, an active power line conditioner, and an active injection mode filter. These five devices were chosen for testing because they were "off-the-shelf" products designed to be installed in various locations, i.e. they were not site specific designs such as a conventional passive filter designed to filter a specific harmonic, i.e. fifth or seventh.
The devices were installed in Department of Energy facilities in Oak Ridge, Tennessee, that had existing single-phase nonlinear loads (switch mode power supplies and uninterruptible power supplies) on a 3-phase, 4-wire 120/208 V system.

\section{Tests of HaRmonic Mitigation Devices}

\section{A. Passive Series-Shunt Filter}

A three-phase four-wire, $120 / 208 \mathrm{~V}, 80 \mathrm{~A}$ passive filter advertised as a "harmonic line conditioner" was installed to supply power to two panels which provided electricity to receptacles in several offices. A one line diagram of the location is shown in Fig. 1. Most of the receptacles fed power supplies in computers, video displays, and laser printers which drew a phase current which had a total harmonic distortion (THD) between 75 and 100\%.

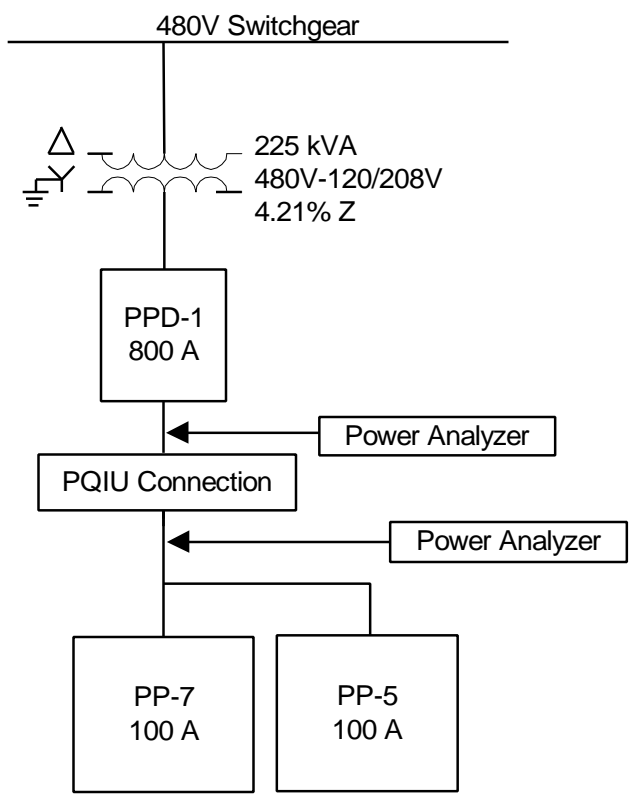

Fig. 1. One line diagram indicating measurement points for tested PQIU's.

* Prepared by the Oak Ridge National Laboratory, Oak Ridge, Tennessee, 37831-6334, managed by Lockheed Martin Energy Research, Inc. for the U.S. Department of Energy under contract DE-AC05-96OR22464. The submitted manuscript has been authored by a contractor of the U.S. Government. Accordingly, the U.S. Government retains a nonexclusive, royalty-free license to publish or reproduce the published from of this contribution, or allow others to do so, for U.S. Government purposes. 


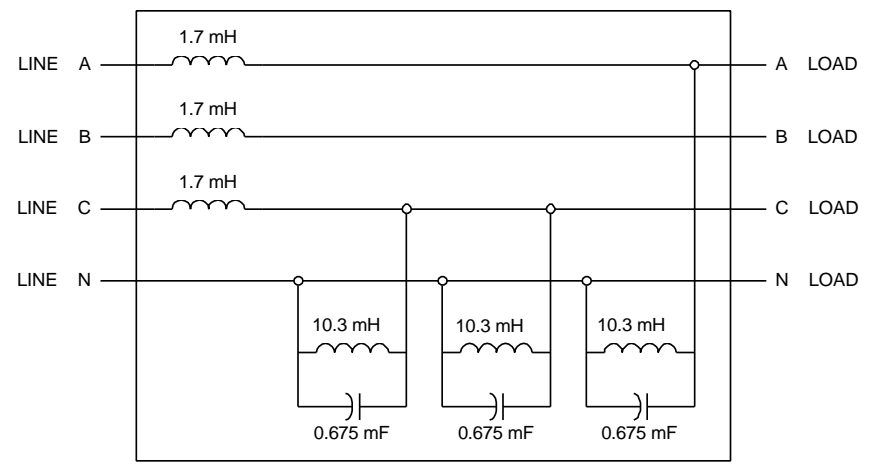

Fig. 2. Circuit schematic for passive filter.

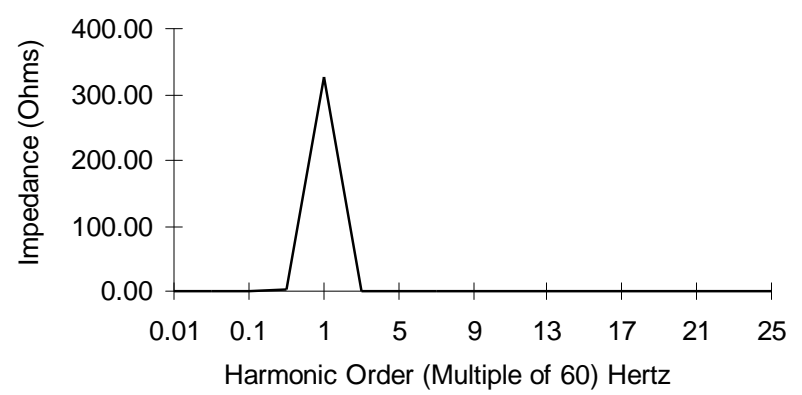

Fig. 3. Impedance of parallel portion of passive filter.

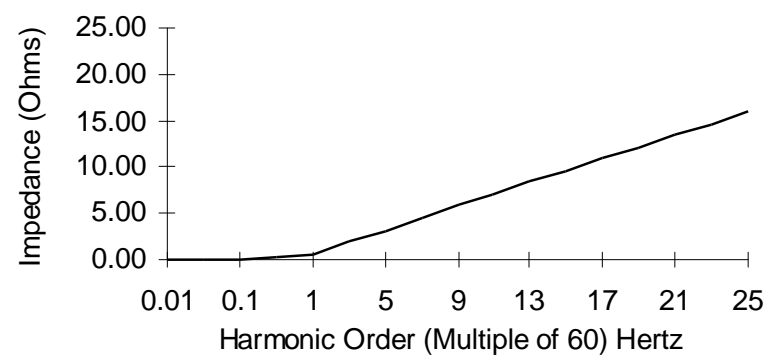

Fig. 4. Impedance of series portion of passive filter.

The filter (shown in Fig. 2) had a series inductance that acted as a low pass filter to prevent higher frequency harmonic currents from passing through the filter and into the upstream distribution system. The parallel part of the filter was designed to shunt the higher frequency current harmonics while allowing the $60 \mathrm{~Hz}$ fundamental current to pass through the filter to the load. Figs. 3 and 4 show the impedance of the parallel and series portion of the filter, respectively.

The installation of the filter did not reduce the harmonic current on the line side of the device, and it actually reduced the RMS line-neutral voltage on the load side (from $120 \mathrm{~V}$ to about $100 \mathrm{~V}$ ) to the point that computers in several of the offices rebooted intermittently due to insufficient voltage. The problem with the filter was that the series inductance caused a voltage drop of approximately 15 percent in the unit.

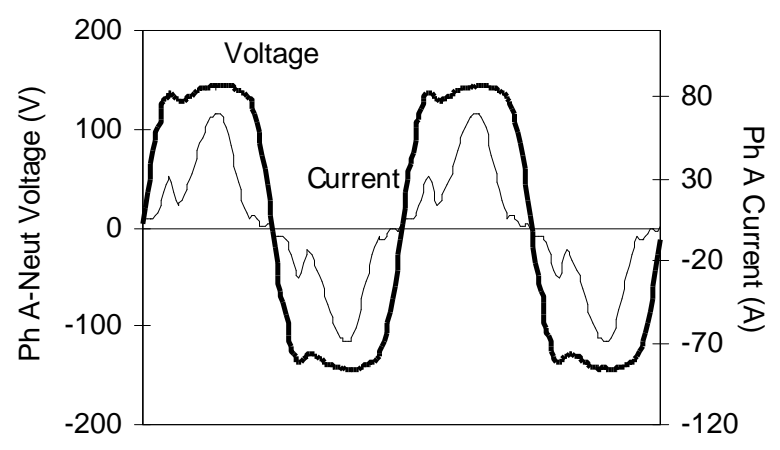

(a)

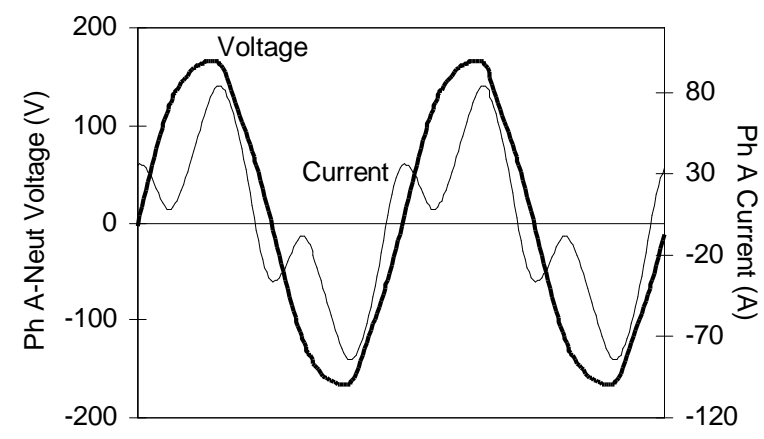

(b)

Fig. 5. Passive filter phase A (a) load and (b) line side waveforms.

Fig. 5 illustrates the effect that the filter had on the electrical system and clearly shows the reduced voltage magnitude (shown by the flat-topped voltage waveforms). The filter did effectively filter out higher order current harmonics; those above the 15 th $(900 \mathrm{~Hz})$ were completely shunted by the parallel filter, and those between the 7th and 15 th were reduced considerably. The filter did not effectively eliminate the load current's third harmonic and acted as a partial "sink" to line side harmonic currents, i.e. some harmonic currents from other panels connected to PPD-1 (Fig. 1) were drawn into the filter instead of propagating back up through the electrical system.

Because of the excessive voltage drop across the series inductance, this element was removed from the filter to see how well it performed as a parallel filter only. Without the series line inductance, no voltage drop problems were encountered; however, the parallel filter acted as a sink to higher order harmonic currents from the load and line side of the filter as shown by the waveforms in Fig. 6 .

\section{B. Delta-Wye Transformers}

All two winding transformers may be called isolation transformers because the primary and secondary of the transformer are coupled magnetically instead of by a directly wired connection such as in an autotransformer. Delta-wye transformers (primary delta, secondary wye) are an effective means of reducing zero sequence harmonic currents from the 


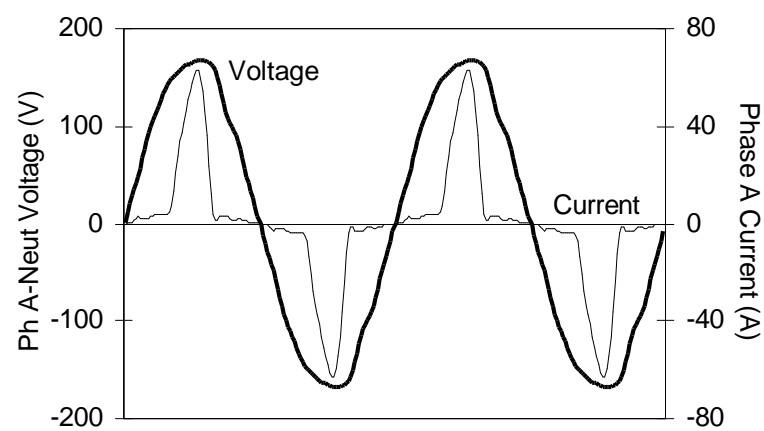

(a)

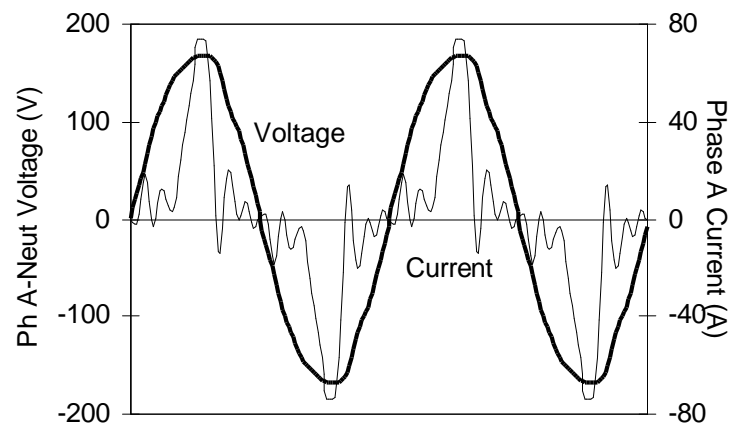

(b)

Fig. 6. Passive filter without series inductance (a) load and (b) line waveforms.

secondary to the primary side of the transformer because the triplen harmonics circulate in the delta (primary side) of the transformer and do not show up on the line side of the transformer. Eliminating these triplen harmonics often can reduce the current THD by as much as $50 \%$ [3].

Placing a copper shield between the primary and secondary of a two winding transformer can also help to prevent common mode noise from being transferred from the secondary to the primary and vice versa. Common mode noise is noise that appears equally and in phase from each currentcarrying conductor to ground [4].

Two different transformers were tested for their ability to reduce harmonic current from the secondary of the transformer to the primary. One transformer tested was a typical dry type distribution transformer currently in service. This $225 \mathrm{kVA}, 480 \mathrm{~V}-120 / 208 \mathrm{~V}$ transformer (Fig. 1) had a nameplate impedance of $4.21 \%$ and fed an 800 A distribution panel which fed a dozen other panels responsible for the primary electrical distribution to the offices in the building. In Fig. 7, waveforms from one phase of the primary and secondary of the transformer are shown. The current THD was reduced by approximately $50 \%$ from the secondary side of the transformer to the primary side because of the nearelimination of the triplen harmonics. The 3rd harmonic on the secondary side of the transformer had a magnitude of $51.8 \%$ of the fundamental. The 3rd harmonic on the primary side of the transformer had a magnitude of only $4.8 \%$ of the fundamental. All other triplen harmonics (9th, 15th, 21st, etc.) on the primary side of the transformer had magnitudes

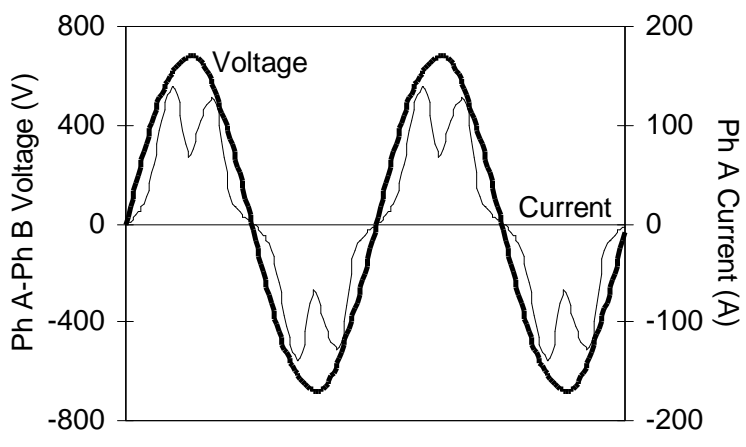

(a)

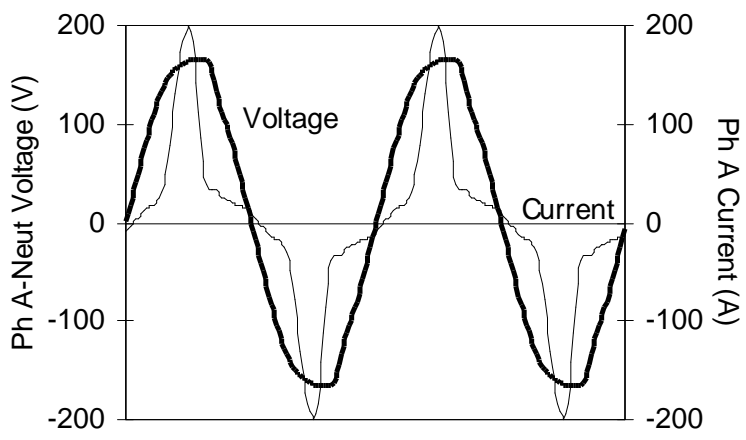

(b)

Fig. 7. Delta-wye transformer (a) primary (line) and (b) secondary (load) waveforms.

TABLE I.

TriPlen Harmonic Reduction With Delta-Wye Transformation

\begin{tabular}{||c||c|c||c|c||c|c||}
\hline \multirow{2}{*}{} & \multicolumn{2}{|c|}{$\begin{array}{c}\text { Ph A Current } \\
\text { Spectrum }\end{array}$} & \multicolumn{2}{c||}{$\begin{array}{c}\text { Ph B Current } \\
\text { Spectrum }\end{array}$} & \multicolumn{2}{|c||}{$\begin{array}{c}\text { Ph C Current } \\
\text { Spectrum }\end{array}$} \\
\cline { 2 - 7 } Harmonic: & $\begin{array}{c}\text { Xfmr } \\
\text { Pri }\end{array}$ & $\begin{array}{c}\text { Xfmr } \\
\text { Sec }\end{array}$ & $\begin{array}{c}\text { Xfmr } \\
\text { Pri }\end{array}$ & $\begin{array}{c}\text { Xfmr } \\
\text { Sec }\end{array}$ & $\begin{array}{c}\text { Xfmr } \\
\text { Pri }\end{array}$ & $\begin{array}{c}\text { Xfmr } \\
\text { Sec }\end{array}$ \\
\hline THD: & 30.1 & 63.5 & 26.2 & 40.4 & 33.7 & 44.1 \\
\hline 3rd & $\mathbf{4 . 8}$ & $\mathbf{5 1 . 8}$ & $\mathbf{3 . 2}$ & $\mathbf{3 2 . 9}$ & $\mathbf{2 . 3}$ & $\mathbf{3 7 . 6}$ \\
\hline 5th & 26.6 & 32.4 & 24.0 & 20.9 & 30.6 & 20.4 \\
\hline 7th & 12.4 & 14.8 & 9.1 & 9.0 & 12.7 & 8.9 \\
\hline 9th & $\mathbf{0 . 4}$ & $\mathbf{6 . 0}$ & $\mathbf{0 . 4}$ & $\mathbf{4 . 1}$ & $\mathbf{0 . 0}$ & $\mathbf{4 . 5}$ \\
\hline 11th & 3.3 & 4.5 & 3.2 & 2.8 & 3.9 & 2.6 \\
\hline 13th & 2.6 & 3.1 & 1.8 & 1.8 & 2.5 & 1.7 \\
\hline 15th & $\mathbf{0 . 5}$ & $\mathbf{1 . 7}$ & $\mathbf{0 . 0}$ & $\mathbf{1 . 3}$ & $\mathbf{0 . 4}$ & $\mathbf{1 . 5}$ \\
\hline \hline
\end{tabular}

less than $1 \%$ of the fundamental. Table $\mathrm{I}$ is a compilation of the harmonic components of the current for the primary and secondary side of the transformer.

A new 30 kVA, $208 \mathrm{~V}$ - 120/208 V, shielded, delta-wye transformer was also tested for its ability to reduce current harmonics. The transformer was connected to the existing distribution system and fed the same receptacle load that the passive filter did (Fig. 1). The transformer was tested with its secondary neutral bonded to ground and with it not bonded (floating).

Results of this shielded transformer did not differ much from the larger non-shielded building transformer. The 
current current third harmonic was reduced by approximately 90 percent from the secondary (load) side of the transformer to the primary (line) side of the transformer due to the deltawye transformation. The ninth harmonic was also considerably reduced from the secondary of the transformer to the primary. The other harmonics did not differ greatly from the secondary side of the transformer to the primary side. Again, the current's total harmonic distortion was reduced by approximately 50 percent because of the near-elimination of triplen harmonics.

With the secondary neutral and ground bonded, the transformer was slightly more effective at reducing harmonics than without the bond. Without this bond, the neutral developed a 20 V RMS difference between it and the ground.

The National Electrical Code requires that the two be bonded because the secondary of the transformer is a separately derived system [5].

\section{Active Power Line Conditioner}

Fig. 8 shows a simplified schematic of an active power line conditioner (APLC) circuitry. The insulated gate bipolar transistors (IGBT's) in the parallel portion of the filter maintain the charge to the dc bus capacitor. The parallel filter also injects the harmonic currents demanded by the load thereby eliminating them from the source current. The series filter compensates for input voltage fluctuations in $V_{i}$ to produce a constant sinusoidal voltage waveform, $V_{o}$, through the buck/boost transformer.

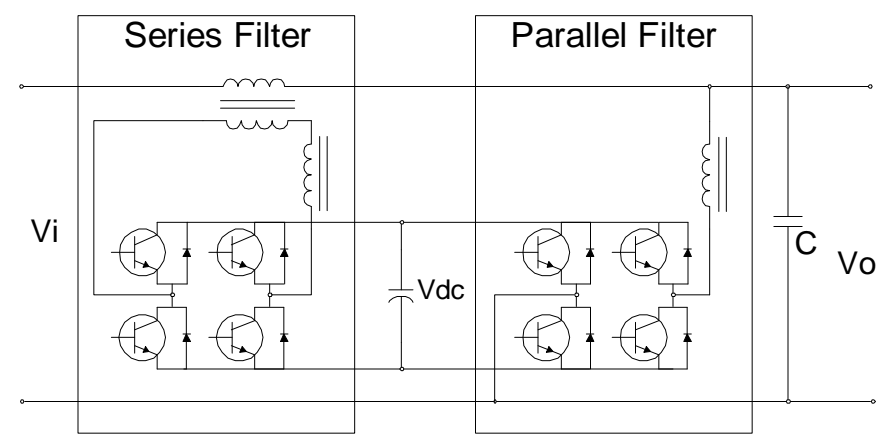

Fig. 8. APLC series and parallel power circuits.

Two different test cases were studied with an APLC: one was a single phase load; the other was a three phase load where three single phase APLC's were connected in a wyewye arrangement to supply the load.

A $120 \mathrm{~V}$, single phase, $5 \mathrm{kVA}$ APLC was tested with a load of two personal computers, two video displays, and two laser printers. The APLC reduced the THD of the current from the load side to the line side from $118.4 \%$ to only $6.3 \%$. In addition, the APLC was supplied with a voltage that had a THD of $2.7 \%$, yet it provided the load with a voltage that was perfectly sinusoidal (THD of $0 \%$ ). This particular APLC drew a current that was close to a $60 \mathrm{~Hz}$ sine wave which enabled a reduction in the crest factor of the load from 2.5 to 1.1.

Also tested were three $5 \mathrm{kVA}$ single phase APLC's wired in

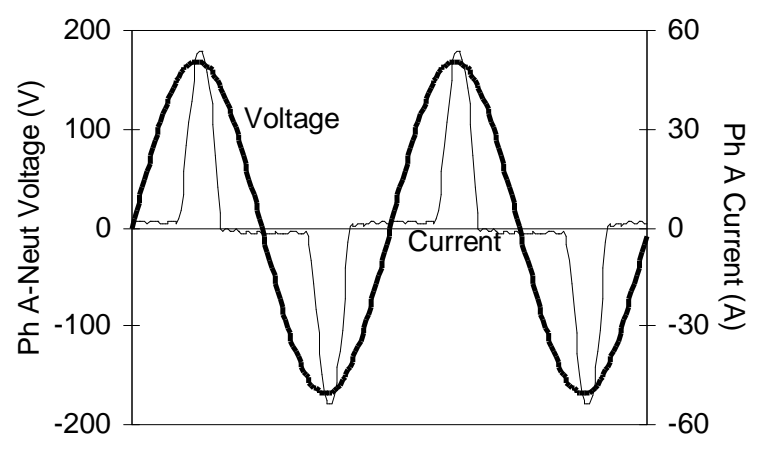

(a)

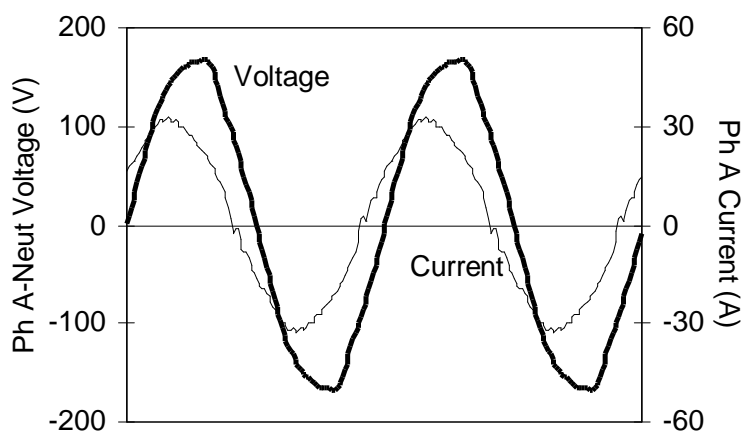

(b)

Fig. 9. Phase A waveforms on the (a) load and (b) line side of a wye-wye threephase bank of active power line conditioners.

TABLE II.

HARMONIC CURRENT REDUCTION WITH Wye-Wye APLC's

\begin{tabular}{||c||c|c|c||c|c|c||}
\hline \multirow{2}{*}{} & \multicolumn{2}{|c|}{ Ph A Current Spectrum } & \multicolumn{2}{c||}{ Neut Current Spectrum } \\
\cline { 2 - 7 } & $\begin{array}{c}\text { APLC } \\
\text { Load }\end{array}$ & $\begin{array}{c}\text { APLC } \\
\text { Line }\end{array}$ & $\begin{array}{c}\% \\
\text { Change }\end{array}$ & $\begin{array}{c}\text { APLC } \\
\text { Load }\end{array}$ & $\begin{array}{c}\text { APLC } \\
\text { Line }\end{array}$ & $\begin{array}{c}\% \\
\text { Change }\end{array}$ \\
\hline THD: & 102.2 & 5.3 & $-95 \%$ & 683.2 & 243.1 & $-64 \%$ \\
\hline Crest Factor & 2.16 & 1.47 & $-32 \%$ & 1.65 & 1.40 & $-15 \%$ \\
\hline Amps(RMS) & 23.4 & 22.5 & $-4 \%$ & 42.3 & 24.3 & $-43 \%$ \\
\hline Harmonic: & & & & & & \\
\hline 3rd & 81.4 & 0.8 & $-99 \%$ & 679.8 & 238 & $-65 \%$ \\
\hline 5th & 54.4 & 3.5 & $-94 \%$ & 37.7 & 20.2 & $-46 \%$ \\
\hline 7th & 26.8 & 0.7 & $-97 \%$ & 37.3 & 12.6 & $-66 \%$ \\
\hline 9th & 6.3 & 1.2 & $-81 \%$ & 10.2 & 32.8 & $222 \%$ \\
\hline 11th & 4.8 & 1.5 & $-69 \%$ & 23.5 & 4.6 & $-80 \%$ \\
\hline 13th & 6.5 & 0.9 & $-86 \%$ & 21.4 & 8.1 & $-62 \%$ \\
\hline 15th & 3.5 & 0.6 & $-83 \%$ & 16.8 & 20.3 & $21 \%$ \\
\hline 17th & 1.6 & 1.2 & $-25 \%$ & 10.6 & 6.7 & $-37 \%$ \\
\hline 19th & 2.2 & 1.1 & $-50 \%$ & 5.4 & 5.3 & $-2 \%$ \\
\hline 21st & 1.7 & 0.8 & $-53 \%$ & 11.8 & 11.4 & $-3 \%$ \\
\hline \hline
\end{tabular}

a wye-wye configuration to provide power to the same load shown in Fig. 1. The voltage and current waveforms for one phase on the input and output of the APLC configuration are depicted in Fig. 9. The units were able to reduce the current THD from their load side to the line side from $102.2 \%$ to 
$5.3 \%$. In addition, RMS neutral current was reduced by $43 \%$ from the load side of the bank to the line side. Table II shows the reduction for specific current harmonics for one phase and the neutral for the wye-wye configuration of APLC's.

The wye-wye configuration of APLC's provided a distortion-free voltage that varied by less than \pm 1 Volt around a nominal voltage value of $120 \mathrm{~V}$ during the two months of continuous testing.

\section{Ferroresonant Magnetic Synthesizer}

The block diagram of the major components in a commercial ferroresonant magnetic synthesizer (FMS) is shown in Fig. 10. An FMS generates an output voltage waveform by combining pulses from six interconnected saturating pulse transformers much like a step wave inverter but without any switching. Energy oscillates between the main capacitor banks and the pulse transformers' cores. This ferroresonance ensures that the transformers' cores saturate and produce the desired voltage pulse. Pulses of different magnitudes are combined to produce an output waveform that has approximately $2.5 \%$ THD and is independent of the input voltage distortion.

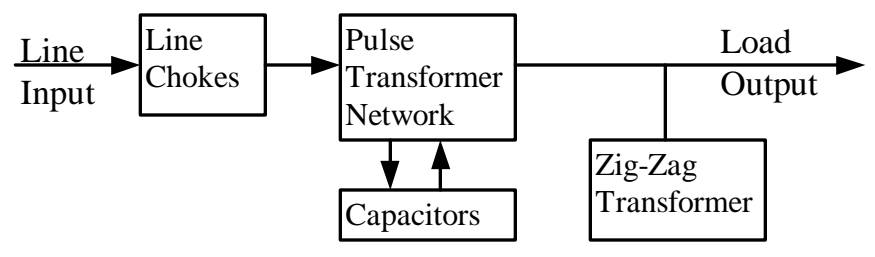

Fig. 10. Block diagram of the major components in a FMS.

The input waveform drawn by the FMS is a function of the way the synthesizing network demands energy from the supply rather than as a function of the load current waveform. This keeps the input current distortion to less than $8 \%$ THD regardless of the load current distortion or phase unbalance. The FMS was originally designed as a regulated power supply for computer centers instead of an active power conditioner because it provides isolation from the input voltage source and can regulate the output voltage to within $5 \%$ of a nominal value with up to a $40 \%$ deviation in the magnitude of the source voltage.

A $30 \mathrm{kVA}, 480 \mathrm{~V}$ 3-wire input, 120/208 V 4-wire output FMS was tested for a six week duration on the load depicted in Fig. 1. Fig. 11 shows snapshots of voltage and current waveforms from the line and load side of the FMS. Current THD was reduced by over $90 \%$ from the load side of the FMS to the line side. No harmonic currents were found on the line side for frequencies above $720 \mathrm{~Hz}$ even though the load had harmonic currents through $1740 \mathrm{~Hz}$. Table III is a compilation of the harmonic components for the currents on the line and load side of the FMS.

IEEE IAS Annual Meeting, Oct. 6-10, 1996, San Diego, CA, pp. 2340-2346

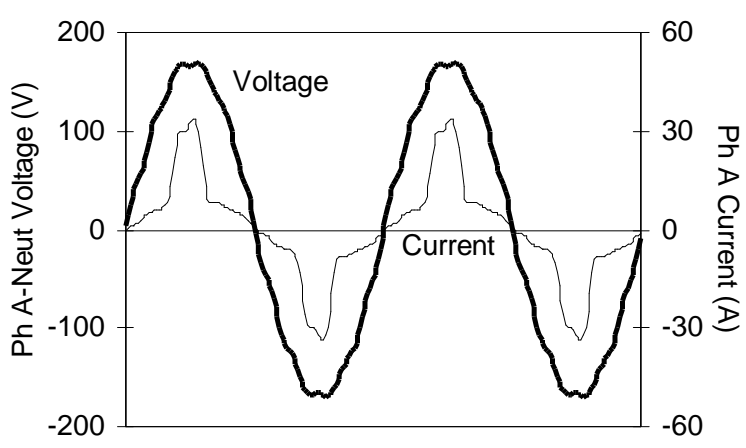

(a)

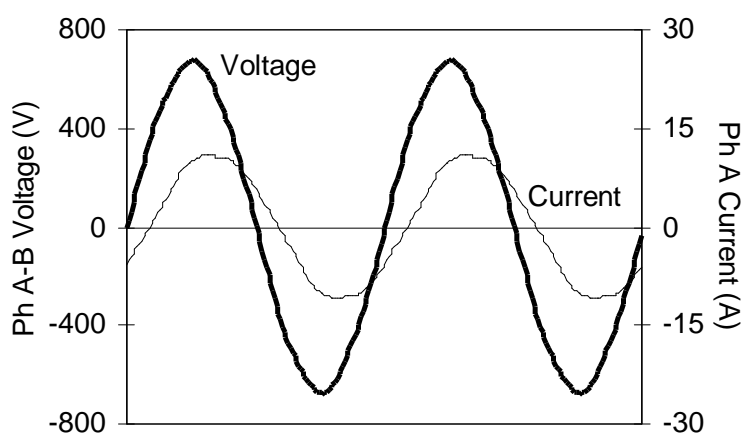

(b)

Fig. 11. Waveforms for the (a) 120/208 V load and (b) $480 \mathrm{~V}$ line side of a ferroresonant magnetic synthesizer.

TABLE III.

HARMONIC CURRENT REDUCTION WITH FMS

\begin{tabular}{||c||c|c||c|c||c|c||}
\hline \multicolumn{1}{||c||}{} & \multicolumn{2}{|c||}{$\begin{array}{c}\text { Ph A Current } \\
\text { Spectrum }\end{array}$} & \multicolumn{2}{c||}{$\begin{array}{c}\text { Ph B Current } \\
\text { Spectrum }\end{array}$} & \multicolumn{2}{c||}{$\begin{array}{c}\text { Ph C Current } \\
\text { Spectrum }\end{array}$} \\
\cline { 2 - 7 } Harmonic: & $\begin{array}{c}\text { FMS } \\
\text { Line }\end{array}$ & $\begin{array}{c}\text { FMS } \\
\text { Load }\end{array}$ & $\begin{array}{c}\text { FMS } \\
\text { Line }\end{array}$ & $\begin{array}{c}\text { FMS } \\
\text { Load }\end{array}$ & $\begin{array}{c}\text { FMS } \\
\text { Line }\end{array}$ & $\begin{array}{c}\text { FMS } \\
\text { Load }\end{array}$ \\
\hline THD: & 3.6 & 63.7 & 4.0 & 83.8 & 3.9 & 65.0 \\
\hline 3rd & 2.1 & 50.1 & 2.1 & 66.1 & 2.2 & 50.9 \\
\hline 5th & 2.8 & 33.7 & 3.4 & 43.9 & 3.1 & 35.3 \\
\hline 7th & 0.4 & 14.4 & 0.3 & 18.7 & 0.3 & 14.4 \\
\hline 9th & 0.0 & 3.0 & 0.0 & 4.3 & 0.0 & 0.8 \\
\hline 11th & 0.9 & 8.6 & 0.9 & 10.5 & 0.9 & 7.8 \\
\hline 13th & 0.0 & 8.4 & 0.0 & 11.9 & 0.0 & 8.7 \\
\hline 15th & 0.0 & 5.7 & 0.0 & 8.8 & 0.0 & 5.8 \\
\hline 17th & 0.0 & 1.4 & 0.0 & 3.1 & 0.0 & 1.0 \\
\hline 19th & 0.0 & 1.1 & 0.0 & 0.7 & 0.0 & 1.4 \\
\hline 15th & 0.0 & 2.1 & 0.0 & 2.1 & 0.0 & 2.0 \\
\hline \hline
\end{tabular}

\section{E. Active Injection Mode Filter}

Active injection mode filters (AIMF's) are connected in parallel with a harmonics load instead of in series like the previously discussed devices. The AIMF switches in varying amounts of current to cancel the harmonic currents demanded by a nonlinear load through the use of a pulse width modulation (PWM) scheme and IGBT switches. This parallel connection results in a reduction of the current carrying 
capacity of many of the components of the AIMF because they only conduct the compensating portion of the total current drawn by the load. The particular unit tested uses clamp-on current transformers on each of the three phases of a nonlinear load to measure the amplitude and phase angle of each current harmonic. The unit then draws a pulse of current of equal amplitude and opposite phase angle.

An AIMF rated to compensate for a 100 A harmonic current load at $120 / 208 \mathrm{~V}$ was connected at a different site from the one depicted in Fig. 1 but with a similar load profile. Fig. 12 shows the voltage and current waveforms for the load and line side of the AIMF. It reduced the current THD from $98.8 \%$ to $9.9 \%$. The unit also reduced the crest factor of the current from 2.5 to 1.5 and the distortion factor from 1.6 to 1.1. The AIMF improved the power factor from 0.65 to 0.98 for this particular load test circuit.

One drawback of the AIMF was that it injected between 10 $\mathrm{V}$ and $20 \mathrm{~V}$ RMS of high frequency noise at the $10 \mathrm{kHz}$ PWM switching frequency of its IGBT's into the electrical system. The AIMF superimposed a $10 \mathrm{~V}$ RMS $10 \mathrm{kHz}$ waveform on the $60 \mathrm{~Hz}$ system voltage waveform. Table IV shows the reduction for specific current harmonics for one phase and the neutral for the AIMF. The unit was most effective at reducing the lower frequency harmonics (3rd through the 11th).

\section{COMPARISON OF Tested DeVICES}

Although the main purpose of testing was to see how much the units canceled harmonic currents, the five different power quality improvement units were also compared in the other following categories: supply of a nondistorted waveform, supply of a regulated voltage, softening agent for impulses and transients, reliability, efficiency, cost, and size. Because the passive filter worsened the conditions instead of improving them, it is not considered in the following discussion. Table $\mathrm{V}$ is a summary of the comparison of the different harmonic suppression units.

\section{A. Cancellation of Harmonic Currents}

The ferroresonant magnetic synthesizer performed best in near elimination of harmonic currents drawn by a load. The saturating transformers in the unit drew a balanced current that had less than 5\% THD while supplying a load that demanded a current with near 100\% THD. Because the input to the unit was $480 \mathrm{~V}$ three-phase without a neutral, the neutral current from the load was also canceled. The wye-wye configuration of single phase active power line conditioners came in a close second by canceling the harmonic current to a point that the unit drew a current with only 6\% THD. However, because the configuration was wye-wye, the neutral current was reduced by $43 \%$ and not totally eliminated. It is recommended that for three-phase applications, a three-phase APLC be used because it would eliminate the neutral current much like the FMS.

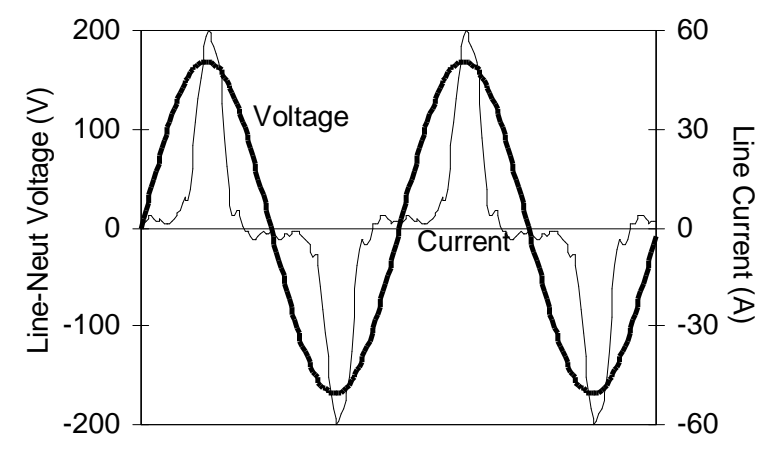

(a)

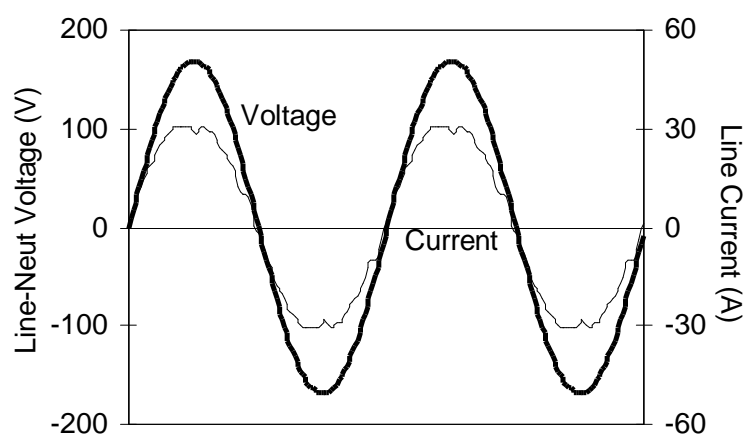

(b)

Fig. 12. AIMF (a) load and (b) line voltage and current waveforms.

TABLE IV.

HaRMonic CuRRENT REDUCTION WITH AIMF

\begin{tabular}{||c||c|c|c||c|c|c||}
\hline \multirow{2}{*}{ Harmonic } & \multicolumn{2}{|c|}{ Ph A Current Spectrum } & \multicolumn{2}{|c||}{ Neut Current Spectrum } \\
\cline { 2 - 7 } & $\begin{array}{c}\text { APLC } \\
\text { Load }\end{array}$ & $\begin{array}{c}\text { APLC } \\
\text { Line }\end{array}$ & $\begin{array}{c}\% \\
\text { Change }\end{array}$ & $\begin{array}{c}\text { APLC } \\
\text { Load }\end{array}$ & $\begin{array}{c}\text { APLC } \\
\text { Line }\end{array}$ & $\begin{array}{c}\% \\
\text { Change }\end{array}$ \\
\hline \% THD: & 98.8 & 9.9 & $-90 \%$ & 565.7 & 104.2 & $-82 \%$ \\
\hline 3rd & 72.9 & 6.5 & $-91 \%$ & 554.6 & 98.7 & $-82 \%$ \\
\hline 5th & 55.3 & 2.2 & $-96 \%$ & 37.0 & 5.2 & $-86 \%$ \\
\hline 7th & 33.1 & 3.1 & $-91 \%$ & 24.7 & 12.8 & $-48 \%$ \\
\hline 9th & 15.6 & 4.2 & $-73 \%$ & 97.3 & 24.8 & $-75 \%$ \\
\hline 11th & 5.4 & 3.8 & $-30 \%$ & 10.9 & 5.3 & $-51 \%$ \\
\hline 13th & 1.7 & 1.3 & $-24 \%$ & 8.7 & 13.2 & $52 \%$ \\
\hline 15th & 1.6 & 1.6 & $0 \%$ & 19.0 & 9.9 & $-48 \%$ \\
\hline 17th & 1.7 & 2.1 & $24 \%$ & 13.7 & 4.0 & $-71 \%$ \\
\hline 19th & 2.8 & 0.7 & $-75 \%$ & 2.1 & 3.1 & $48 \%$ \\
\hline \hline
\end{tabular}

Through the injection of canceling currents, the active injection mode filter reduced harmonic distortion on the line side of the unit to less than $10 \%$. The delta-wye transformer is not an active device, but it inherently cancels triplen harmonics. For electrical distribution systems that have a substantial number of single phase harmonic producing loads, a delta-wye transformer may reduce THD by approximately $50 \%$. Because three phase harmonic loads do not produce triplen harmonics, a delta-wye transformer would be of little value in these cases. 
TABLE V.

Comparative Summary of Power Quality Improvement Unit Performance

\begin{tabular}{|c|c|c|c|c|c|c|c|c|c|c|c|c|}
\hline \multirow{2}{*}{$\begin{array}{l}P=\text { Poor, } F=\text { Fair, } G=\text { Good } \\
\text { Performance Factors }\end{array}$} & \multicolumn{3}{|c|}{ Xfmr } & \multicolumn{3}{|c|}{ APLC } & \multicolumn{3}{|c|}{ FMS } & \multicolumn{3}{|c|}{ AIMF } \\
\hline & $P$ & $F$ & $G$ & $P$ & $F$ & $G$ & $P$ & $F$ & $G$ & $P$ & $F$ & $G$ \\
\hline Harmonic Current Cancellation & & $\mathbf{X}$ & & & & $\mathbf{X}$ & & & $\mathbf{X}$ & & & $\mathbf{X}$ \\
\hline Supply of Nondistorted Voltage & $\mathbf{X}$ & & & & & $\mathbf{X}$ & & $\mathbf{X}$ & & $\mathbf{X}$ & & \\
\hline Supply of a Regulated Voltage & $\mathbf{X}$ & & & & & $\mathbf{X}$ & & $\mathbf{X}$ & & $\mathbf{X}$ & & \\
\hline Softening Agent for Impulses & & $\mathbf{X}$ & & & & $\mathbf{X}$ & & & $\mathbf{X}$ & $\mathbf{X}$ & & \\
\hline Reliability & & & $\mathbf{X}$ & & $\mathbf{X}$ & & & & $\mathbf{X}$ & & $\mathbf{X}$ & \\
\hline Efficiency & & $\mathbf{X}$ & & & $\mathbf{X}$ & & $\mathbf{X}$ & & & & & $\mathbf{X}$ \\
\hline Cost & & & $\mathbf{X}$ & $\mathbf{X}$ & & & & $\mathbf{X}$ & & $\mathbf{X}$ & & \\
\hline Size and Weight & & & $\mathbf{X}$ & & $\mathbf{X}$ & & $\mathbf{X}$ & & & & & $\mathbf{X}$ \\
\hline
\end{tabular}

\section{B. Supply of a Nondistorted Voltage Waveform}

The APLC supplied a voltage waveform that was essentially distortion free (THD equal to zero). It also did not inject any high frequency noise into the electrical system. The FMS supplied a voltage that had approximately $2.5 \%$ THD regardless of the distortion of the voltage source.

The delta-wye transformer is at the mercy of the incoming voltage distortion because it is reflected to the secondary of the transformer and to the load. The AIMF is a parallel connected device and really has no effect on voltage distortion other than through the effect that diminished harmonic currents have on the electrical distribution system. In addition, the AIMF injected 10 to $20 \mathrm{~V}$ of high frequency noise into the distribution system that could be measured at upstream switchgear equipment.

\section{Supply of a Regulated Voltage}

The APLC regulated the output voltage to within $1 \%$ of a nominal value for input variations of $+15 \%$ to $-50 \%$. The FMS was capable of producing an output voltage within 5\% of a nominal value for input variations of $+40 \%$ to $-40 \%$.

The delta-wye transformer is again at the mercy of the voltage source because its output voltage is related to input voltage simply by the turns ratio. The AIMF does not regulate the output voltage either because it is connected in parallel across the line.

\section{Softening Agent for Impulses and Transients}

The APLC and FMS have built-in transient surge suppressors to prevent impulses from reaching connected equipment. The transformer is a softening agent between the source and the load, but it cannot completely eliminate transients. The tested AIMF does not have transient surge suppressant capability.

\section{E. Reliability}

While no long term testing was performed on the equipment as part of this study, some insight into reliability was gained during the time that the equipment was in service. Delta-wye transformers have been built for decades and have no electronic devices or moving parts associated with them. If transformers are not overloaded such that their insulation integrity is maintained, they will easily last 30 years. The main power devices in the FMS are transformers which should also be fairly rugged. The FMS does have some control circuits and filtering capacitors which would add to the number of possible devices that might fail. The FMS has been in production for over 10 years, so flaws in design and production should have been corrected by now.

The APLC and AIMF both use power electronics (IGBT's) and sophisticated control techniques to compensate for harmonic currents. Both of these power quality improvement units and their internal electronics are relatively new devices and have yet to "stand the test of time". One of the three APLC's in the wye-wye configuration had a premature failure during the two months that it was in service [1].

\section{F. Efficiency}

The AIMF corrects power factor to unity, and most of the current drawn by the unit is reactive to compensate for motor loads or to cancel unwanted harmonic currents. Most of the losses in the AIMF come from switching losses which is minimal compared to the total power. The APLC reduced the crest factor of current drawn considerably and the RMS value of current only slightly. The wye-wye configuration of single phase APLC's did not draw a current that had unity power factor, however. Again like an AIMF, most of the losses in the APLC come from small switching losses.

Delta-wye transformers have an inherent impedance associated with them on the order of 5\% which causes resistive heating. Also, harmonic currents cause eddy losses proportional to their frequency squared. This means that higher order harmonics are much more lossy than and cause much more heating than the fundamental current. Finally, triplen harmonics circulate in the delta windings of the transformer and cause heat losses. All of these heating effects tend to lessen the life of the insulation of the transformer.

The FMS drew a balanced current that had a power factor close to unity. However, the saturating transformers in the FMS were quite lossy because the unit tested was really hot when in operation; even hotter than a comparable delta-wye transformer. This heat must be taken into account when using an FMS; and to the manufacturer's credit, the company publishes the expected heat loss in BTU's/hour for each of their units.

\section{G. Cost, Weight, and Size}

Table VI lists cost, weight, and size information for each of the tested PQIU's. All of the devices tested were in the 30 $50 \mathrm{kVA}$ size range. The shielded, filtered delta-wye transformer was the least expensive of the devices tested. Costing four to five times what a specialty transformer costs, the AIMF and APLC were the more expensive power quality improvement units tested. The FMS weighed considerably more than all of the other PQIU's. 
TABLE VI.

Cost, WeIGHT, AND SIZE INFORMATION FOR PQIU'S

\begin{tabular}{|c|c|c|c|c|}
\hline & Xfmr & FMS & AIMF & APLC \\
\hline Cost/kVA & $\$ 95$ & $\$ 330$ & $\$ 430$ & $\$ 460$ \\
\hline kg/kVA & 4.5 & 33.7 & 2.8 & 10.0 \\
\hline Height $(\mathrm{cm})$ & 76.2 & 162.6 & 182.9 & 182.9 \\
\hline Width $(\mathrm{cm})$ & 76.2 & 91.4 & 76.2 & 121.9 \\
\hline Depth $(\mathrm{cm})$ & 50.8 & 86.4 & 76.2 & 53.3 \\
\hline
\end{tabular}

\section{DESIGNING FOR HARMONICS}

Most electrical systems were not designed to support the nonlinear devices that now make up a large percentage of the loads on today's distribution systems. The National Electrical Code (1996) has yet to directly address many of the issues associated with harmonics. It does now contain, however, a definition for nonlinear load and a couple of fine print notes (FPNs) regarding harmonics in its 1996 edition [5]. Article 220-22 regarding feeder neutral load has the FPN, "A 3phase, 4-wire, wye-connected power system used to supply nonlinear loads may necessitate that the power system design allow for the possibility of high harmonic neutral currents." Article 450-3 regarding overcurrent protection for transformers has the FPN, "Nonlinear loads can increase heat in a transformer without operating its overcurrent protective device." Indirectly, the NEC does address things like oversizing neutral conductors because it requires that conductors be sized to carry expected loads.

Although this study tested transformers which were not Kfactor rated, to meet UL and NEC requirements K-factor transformers must be used for supplying nonlinear loads. Kfactor transformers are UL listed to supply nonlinear loads without loss in the insulation life of the transformer. The Kfactor is found by multiplying the frequency squared for each harmonic component by its per unit amplitude squared and then summing over all harmonic frequencies, $N$ :

$$
K_{-} \text {factor }=\sum_{h=1}^{N}\left(\frac{I_{h}}{I}\right)^{2} h^{2}
$$

Manufacturers charge a premium for K-factor transformers even though some manufacturers have simply derated a larger transformer and had it tested so that it meets UL requirements. True $\mathrm{K}$-factor transformers have neutrals rated at two times the ampacity of the phase conductors, a low flux density core, and are wound with smaller conductors to reduce eddy current losses. True K-factor transformers are 5 $10 \%$ larger than their K-1 (non K-factor) counterparts [6].

When applying power quality improvement units to reduce the level of harmonic currents, these should be placed as close to non-linear loads as possible. This prevents harmonics from propagating throughout the system and interacting with more of the electrical system and connected equipment. Lai and Key [7] have also shown an economic justification for suppressing harmonics as close to their source as practical.

Future designs should follow the guidance given in IEEE 519, Recommended Practices and Requirements for
Harmonic Control in Electrical Power Systems; IEEE 1100, Recommended Practice for Powering and Grounding Sensitive Electronic Equipment; and FIPS 94, Requirements for Data Processing Centers [4,8,9]. All three of these publications contain useful information in the design of electrical systems where nonlinear loads are expected or where loads sensitive to voltage harmonics are located.

Prior to purchasing and installing a power quality improvement unit, several factors should be considered: cancellation of harmonic currents, supply of a nondistorted voltage waveform, supply of a regulated voltage, softening agent for impulses and transients, reliability, efficiency, cost, and size. Each installation is different and all of these factors must be weighed during the selection process in order to choose the unit which best suits the conditions for which it is applied.

\section{CONCLUSIONS}

Test results of five commercially available harmonic mitigation devices are reported in this paper. Passive filters should not be universally applied without careful consideration of their electrical system impact. The test filter actually worsened the electrical system instead of improving it. Delta-wye transformers are a cheap means of eliminating triplen harmonics in 3-phase, 4-wire systems that have several single phase harmonic producing loads. An active injection mode filter can cancel the majority of low frequency current harmonics and greatly improve the power factor of the system.

The ferroresonant magnetic synthesizer and active power line conditioner not only cancel unwanted current harmonics but also supply loads with a regulated, distortion-free voltage. The major drawbacks of the FMS are heat loss and weight. The APLC is the most expensive of the power quality improvement units tested.

\section{REFERENCES}

[1] L. M. Tolbert, "Harmonic Analysis of Electrical Distribution Systems," Oak Ridge National Laboratory, ORNL-6887, March 1996.

[2] L. M. Tolbert, H. Hollis, P. S. Hale, "Survey of Harmonics Measurements in Electrical Distribution Systems," Conf. Record of the 1996 IAS Annual Meeting.

[3] IEEE Task Force, "Effects of harmonics on equipment", IEEE Trans. Power Delivery, vol. 8, pp. 672-680, Apr. 1993.

[4] IEEE Emerald Book, IEEE Recommended Practice for Powering and Grounding Sensitive Electronic Equipment, IEEE Std 1100-1992.

[5] National Electrical Code, NFPA Std 70-1996.

[6] IEEE Recommended Practice for Establishing Transformer Capability When Supplying Nonsinusoidal Load Currents, ANSI/IEEE Std. C57.110-1986.

[7] T. S. Key and J. S. Lai, "Costs and benefits of harmonic current reduction for switch-mode power supplies in a commercial office building", Industrial Applications Society Annual Meeting 1995, pp. 1101-1108, Oct. 1995.

[8] IEEE Recommended Practices and Requirements for Harmonic Control in Electric Power Systems, IEEE Std 519-1992.

[9] Guideline on Electrical Power for ADP Installations, Federal Information Processing Standard Publications 94, National Bureau of Standards, 1983. 